\title{
EVALUATION OF PRODUCT QUALITY WITH DECIBELS
}

\author{
UDC: 005.642 .3 \\ Original Scientific Paper \\ Branko POPOVIĆ ${ }^{1}$ \\ ${ }^{1}$ University of Belgrade, Mechanical Faculty, 11000 Beograd, 16, Kraljice Marije, Republic of Serbia \\ E-mail: branko@popovic.org
}

Paper received: 03.09.2021.; Paper accepted: 16.11.2021.

\begin{abstract}
In modern Quality Engineering, the quality of process results, the quality of measuring instruments, and the quality of completed processes are considered according to their quality characteristics. However, in traditional engineering, only the quality of measuring instruments and the quality of completed processes (precision or accuracy indices PCI, PPI) can be successfully defined, while the quality of process results (semi-finished product, product, software, service) can only be described (has or does not have the required quality), good or bad quality, better or worse quality). In the modern consideration of quality, the quality of process results is now defined by the number of decibels $[\mathrm{dB}]$, according to the discovery of the genius Japanese scientist Genichi Taguchi (1924-2012), with the methods of Robust Technology Development and Standard Ratio $(S / N)$. This paper discusses definition of the quality of process results with one input variable and continuous characteristics with three illustrative examples.
\end{abstract}

Keywords: Quality engineering; Quality of process results; Continual characteristics.

\section{INTRODUCTION}

The business of organization, in order to satisfy users more fully, stakeholders and employees, largely depends on the achieved quality of the results of the process, which is considered in Quality Engineering. The quality of process results is the level to which a set of quality characteristics effectively meets planned requirements and tasks. Quality engineering is a way of approach to predict or prevent problems that may occur in the market, after the customer sells and uses the product in various circumstances and applied conditions, during the projected life of the product. Quality characteristics are more often continual because they can be calculated accurately while discrete characteristics are only estimated. The set of quality characteristics of the process results can be: Semi-finished product, Product, Software or Service. Dependability is the probability to which a process result can perform its function, i. e. a set of characteristic quantities: Availability, Reliability, Safety, Confidentiality, Integrity and Maintainability.
The traditional understanding of quality includes consideration of the quality of process results, the quality of measurement systems, or the quality of completed processes. The quality of measurement systems and completed processes can be defined using a standardized (ISO 8258) process capability index $(P C I) . C p)$ or Process Performance Index, $P P I, P p)$. In consideration of the quality of process results, input quantities can be continuous and attributive, with continuous having a great advantage. Unfortunately, the quality of process results can only be described in attribute terms (quality or poor quality, good or bad quality, better or worse quality, etc.).

Modern understanding of the quality of process results includes definition of quality in decibels [dB], according to the findings of the Japanese scientist Genichi Taguchi (1924-2012), whose methods cover the following main areas:

1. System design with Quality Loss Function (QLF) and Offline Quality Control (System design with Quality Loss Function (QLF) and Offline Quality Control (Logothetis, \& Wynn, 1989; Nair, 1992; Sreenivas et al., 2008; Taguchi, 1986, 1995), 
2. Parameter design with Robust Technology Development and Standard $(S / N)$ Ratio (Taguchi, 1992; Taguchi, \& Rajesh, 2002; Taguchi, Chowdhury, \& Wu, 2000, 2005; G. Taguchi, Rajesh, \& S. Taguchi, 2004; Wu, \& Hamada, 2002),

3. Tolerance design with criteria: Nominal is-best, Less-is-better, and More-better is better (Taguchi, Chowdhury, \& Wu, 2005),

4. Design of experiments (DoE) with an orthogonal sequence of plans and multilevel experiments (Atkinson, Donev, \& Tobias, 2007; Box, \& Draper, 2007; Goos, 2002; Hardin, \& Sloane 1993; Moen, Nolan, \& Provost 1991; Montgomery, 2005; Pukelsheim, 2006).

One of the most important quality assessments with decibels is Phred. A Phred quality score is a measure of the quality of identification of the nucleobases generated by automated DNA sequencing (Hillier \& Green, 1998). It was originally developed for the computer program Phred to help in the automation of DNA sequencing in the Human Genome Project. Phred quality scores are assigned to each nucleotide base call in automated sequencer traces. The FASTQ format encodes Phred scores as ASCII characters alongside the read sequences. Phred quality scores have become widely accepted to characterize the quality of DNA sequences, and can be used to compare the efficacy of different sequencing methods. Perhaps the most important use of Phred quality scores is the automatic determination of accurate, quality-based consensus sequences.

\section{METHODOLOGY}

The standard $S / N$ ratio (signal/noise ratio, $S / N$ ) establishes the appropriate ratio of input quantity $(S)$ and variability $(N)$, which Taguchi used for application in the communications industry, to check the quality of the results. starting from the fact that the radio receives a signal or voice wave emitted from broadcast stations and converts it into sound, the voice is the input quantity (signal), the received voice is the output signal (response), where the input is mixed in space with the variability of the output signal (noise), so the sound quality is expressed by the ratio of the input signal and the variability in decibels $[\mathrm{dB}]$. Of course, the higher the ratio $(S / N)$ the better the quality. The ratio $(S / N)$ has a real value of the input quantity (signal, $S$ ) in the counter and a value of variability of the input quantity (noise, $N$ ) in the denominator, so that higher quality is always obtained with the actual value of input value $(S)$ and the highest value of variability $(N)$.

Primary ratios $(S / N)$ for the quality of process results with continuous characteristics include:

- known true values of the input quantity (zero proportional function, proportional function with reference point, linear function),

- known levels of the magnitude value interval,

- known ratios of $(S / N)$ levels of the input quantity, unknown true values of the input quantity level and

- unknown input quantities (non-dynamic characteristics: nominal is-best, less-is-better, bigger-is-better, non-dynamic operations).

There are many different advantages of primary $(S / N)$ ratios in Quality Engineering but the code is most often defined with regression coefficient $(\beta)$ and variance $\left(\sigma^{2}\right)$ :

$$
\begin{aligned}
& S / N=\frac{\text { power of the input quantity }}{\text { power of variability of the quantity }}= \\
& =\frac{(\text { sensitivity })^{2}}{(\text { variability })^{2}}=\frac{\beta^{2}}{\sigma^{2}} .
\end{aligned}
$$

A factor is any parameter or variable that can affect the operation of a product or process. The signal factor is used to adjust the output (response). The noise factor is an uncontrolled factor that distinguishes levels of quality and products, there are (variability due to external causes: temperature, humidity, operator, vibration, etc., variability due to internal causes: wear, aging, etc. and variability due to differences between parts or products (length, voltage, etc.). Response factor is the output result (response) of the effect. Environmental noise factors are sources of variability due to environmental conditions when using the product. The ideal function is the ideal standard state relationship between the output (response) and the input quantities. Robust technology development is a special approach to maximize the functionality of a product group at the earliest stage, such as those in the product research and development phase, minimizing product development time. Robustness is the condition of using and describing a product plan or process that operates with limited variability, despite different and changing environmental conditions. Robust design is a special process within quality engineering to create a product or process insensitive to variability, without removing 
the source. Signal-to-noise ratio $(S / N)$, the ratio of magnitude to variability, any set of special functions in an experimental design to find the optimal set of factor levels.

The $(S / N)$ ratio in the approach of considering the quality of process results is observed in:

- traditional approach when planning a new product,

- in advanced approach when considering the quality of the whole group of process results with the same function within a certain range,

- dynamic mode when there is a fixed goal and no adjustment is required,

- non-dynamic mode when adjusting the input to the target (nominal-is-best, less-is-better, bigger-is-better),

- generic function with physical laws, objective function when all data is missing,

- an ideal function that is defined on the basis of the process result function,

- with a passive $(S / N)$ ratio with measured values,

- an active $(S / N)$ ratio with an adjusted value input, and

- according to the number of input quantities.

Starting from the collected data on the quality of the process results according to Table 1 , with one input quantity $M_{i}(i=1,2,3, \ldots, k)$ and its values $y_{i j}$ $\left(i=1,2,3, \ldots, . k ; j=1,2,3, . . r_{0}\right)$ and the principal quantities $y_{i}(\mathrm{i}=1,2,3, \ldots, k)$.

Table 1: Input values

\begin{tabular}{|l|l|l|l|l|}
\hline Input values & $\boldsymbol{M}_{\boldsymbol{1}}$ & $\boldsymbol{M}_{\mathbf{2}}$ & & $\boldsymbol{M}_{\boldsymbol{k}}$ \\
\hline \multirow{5}{*}{ Data } & $y_{11}$ & $y_{21}$ & & $y_{k 1}$ \\
\cline { 2 - 5 } & $y_{12}$ & $y_{21}$ & & $y_{k 1}$ \\
\cline { 2 - 5 } & & & & \\
\cline { 2 - 5 } & $y_{110}$ & $y_{2 r 0}$ & & $y_{k r 0}$ \\
\hline Total & $y_{1}$ & $y_{2}$ & & $y_{k}$ \\
\hline
\end{tabular}

The quality of process results with continuous characteristics is most often taken into account when a larger number of data can be seen according to Figure 1. The regression line passes to:

a) zero ideal function through the origin of diagram and reference data $(M=0, y=0)$ usually for measuring instruments,

b) proportional ideal function through the reference point and reference data $\left(M=M_{s}\right.$, $y=\bar{y}_{S}$ ) usually for products or c) linear ideal function through reference $(M=\bar{M}, \quad y=m) \quad$ usually for completed processes.

\section{EXAMPLE FOR ZERO IDEAL FUNCTION}

Evaluation of the quality of process results, for zero proportional function with: input values $M$ $\left(M_{1}, M_{2}, . ., M_{\mathrm{k}}\right)$, input values $y_{i j}(i=1,2, \ldots, k ; j=1$, $\left.2, \ldots, r_{0}\right)$, outputs $y\left(y_{1}, y_{2}, . ., y_{\mathrm{k}}\right)$, and errors $\left(e_{i j}\right)$, include the sum of the squares of the data $(r)$ and the ideal function (Taguchi, \& Rajesh, 2002; G. Taguchi, Rajesh, \& S. Taguchi, 2004):

$$
\begin{aligned}
& r=M_{1}^{2}+M_{2}^{2}+. .+M_{k}^{2}, \\
& y_{i j}=\beta M_{i}+e_{i j} .
\end{aligned}
$$

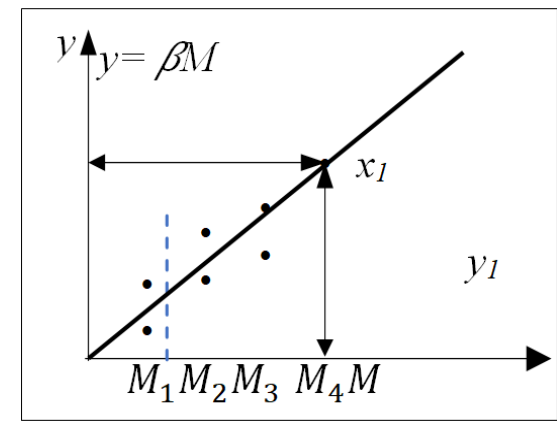

a)

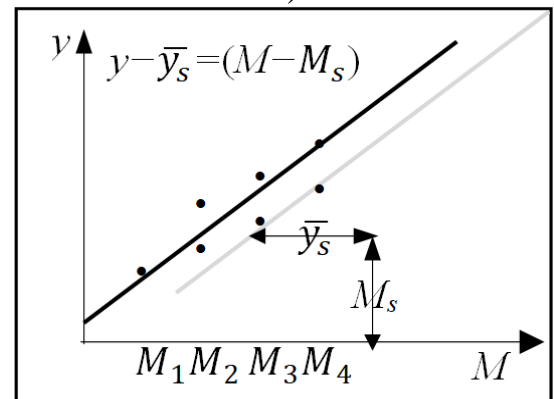

b)

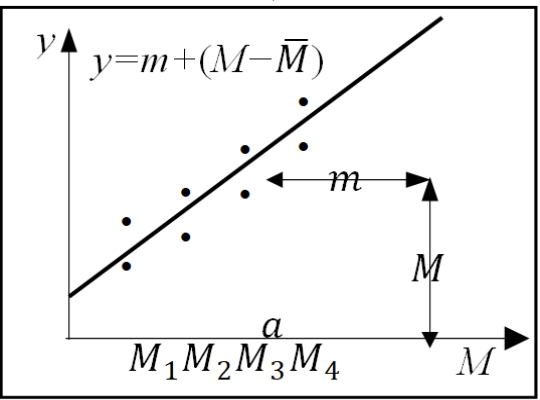

c)

Figure 1: Ideal zero function, proportional function through the reference and linear functions

This function is expressed as a series of simultaneous functions with one unknown $(\beta)$, 
whose value minimizes the total sum of squares of differences $(\mathrm{Se})$ of the function right and left sides, according to the known Least-squares method, and includes: total variability $\left(S_{T}\right)$ with the number of degrees of freedom $\left(f=k_{r 0}\right)$, regression coefficient variability $\left(S_{\beta}\right)$, error variability $\left(S_{e}\right)$, error variability $\left(V_{e}\right)$ and statistical expectation of regression coefficient $E\left(S_{\beta}\right)$, so by definition it gets the true value of the ratio $(S / N)$ in decibels $[d B]$, and the sensitivity $(S)$ is:

$$
\begin{aligned}
& S_{e}=\left(y_{11}-\beta M_{1}\right)^{2}+\left(y_{1} 2-\beta M_{2}\right)^{2}+\ldots \\
& \ldots+\left(y_{k r 0}-\beta M_{k}\right)^{2} \\
& \beta=\frac{1}{r_{0} r}\left(M_{1} y_{1}+M_{2} y_{2}+. .+M_{k} y_{k}\right), \\
& S_{T}=y_{11}^{2}+y_{12}^{2}+. .+y_{k r 0}^{2},\left(f=k_{r 0}\right), \\
& S_{\beta}=\frac{1}{r_{0} r}\left(M_{1} y_{1}+M_{2} y_{2}+. .+M_{k} y_{k}\right)^{2}, \\
& (f=1), \\
& S_{e}=S_{T}-S_{\beta},\left(f=k_{r 0}-1\right), \\
& V_{e}=\frac{S_{e}}{k r_{0}-1}, \\
& E\left(S_{\beta}\right)=r_{0} r \beta^{2}+\sigma^{2}, \\
& S / N=10 \log \frac{\beta^{2}}{\sigma^{2}}=10 \log \frac{\left(\frac{1}{r_{0} r}\right)\left(S_{\beta}-V_{e}\right)}{V_{e}}, \\
& S=10 \log \frac{1}{r_{0} r}\left(S_{\beta}-V_{e}\right) d B .
\end{aligned}
$$

Analysis of variance is essential in the calculation. Analysis of variance (ANOVA) is a collection of statistical models and their associated estimation procedures (such as the variation among and between groups) used to analyze the differences among means. ANOVA is based on the law of total variance, where the observed variance in a particular variable is partitioned into components attributable to different sources of variation. In its simplest form, ANOVA provides a statistical test of whether two or more population means are equal, and therefore generalizes the $t$-test beyond two means. ANOVA was developed by the statistician Ronald Fisher (1890 - 1962).
For example, the quality of a new DENSITY ANALYZER INSTRUMENT should be assessed in relation to the quality of the correct instrument, with an ideal proportional function and with a 5\% reference point of the standard solution. An input quantity with three different densities $(30[\mu \mathrm{m}], 80$ $[\mu \mathrm{m}], 90[\mu \mathrm{m}])$ was observed in Table 2.

Table 2: Measured displacement values

\begin{tabular}{|l|l|l|l|}
\hline Moving & $\mathbf{3 0}[\boldsymbol{\mu m}]$ & $\mathbf{6 0}[\boldsymbol{\mu m}]$ & $\mathbf{9 0}[\boldsymbol{\mu m}]$ \\
\hline \multirow{2}{*}{ Measure } & $65[\mathrm{mV}]$ & $136[\mathrm{mV}]$ & $208[\mathrm{mV}]$ \\
\cline { 2 - 4 } & $74[\mathrm{mV}]$ & $147[\mathrm{mV}]$ & $197[\mathrm{mV}]$ \\
\hline Total & $139[\mathrm{mV}]$ & $283[\mathrm{mV}]$ & $405[\mathrm{mV}]$ \\
\hline
\end{tabular}

Applying the Analysis of Variance, the following values are obtained, shown in Table 3:

$$
\begin{aligned}
& S_{T}=65^{2}+74^{2}+. .+197^{2}=131,879, \\
& r_{0} r=2\left(30^{2}+60^{2}+90^{2}\right)=25,200, \\
& S_{\beta}=\frac{[(30 \cdot 139)+(60 \cdot 283)+(90 \cdot 405)]^{2}}{r_{0} r}= \\
& =131,657.14,(f=1), \\
& S_{e}=131,879-131,657.14= \\
& =221.86,(f=5), \\
& V_{e}=\frac{221.86}{5}=44.37 .
\end{aligned}
$$$$
S / N=\frac{\frac{1}{25,220}(131,657.14-44.37)}{44.37}=
$$$$
=0.1177,
$$$$
S / N=10 \log (0.1177)=-9.29[\mathrm{~dB}],
$$$$
\beta=\frac{57,600}{25,200}=2.285 \text {, }
$$$$
y=2.285 \mathrm{M} \text {. }
$$

Table 3: Analysis variance table

\begin{tabular}{|l|l|l|l|l|}
\hline Factor & $\mathbf{F}$ & $\mathbf{S}$ & $\mathbf{V}$ & $\mathbf{E}[\mathbf{V}]$ \\
\hline$\beta$ & 1 & $131,657.14$ & $131,657.14$ & $\sigma^{2}+r_{0} r \beta^{2}$ \\
\hline$e$ & 5 & 221.86 & 44.37 & $\sigma^{2}$ \\
\hline Total & 6 & $131,879.00$ & & \\
\hline
\end{tabular}

The following is obtained: calculated $(S / N=-9.29$ $[\mathrm{dB}])$ ratio, estimated regression coefficient $(\beta=$ 
$2.285)$ and dependence function $(y=2.285 M)$.

After the calculation, it was determined that the quality of the new DENSITY ANALYZER INSTRUMENT with three different densities (30 $[\mu \mathrm{m}], 80[\mu \mathrm{m}], 90[\mu \mathrm{m}])$ cannot be compared with the correct instrument, due to the negative and small value of the ratio $(S / N=-9.29[\mathrm{~dB}])$.

\section{EXAMPLE OF IDEAL PROPORTIONAL FUNCTION AND REFERENCE POINT}

Evaluation of the quality of process results, with an ideal proportional function and a reference point, usually occurs in products, when a regression line with a linear regression coefficient $(\beta)$ passes through the reference point and reference data. The product quality is calculated with calibration according to the reference point $\left(M_{s}\right)$, with two types of calibration according to point calibration and according to the slope calibration (Rosa et al., 2009).

Evaluation of product quality in the proportional function includes: input value $M\left(M_{1}, M_{2}, . ., M_{\mathrm{k}}\right)$, input values $y_{i j}\left(i=1,2, \ldots, k ; j=1,2, \ldots, r_{0}\right)$, reference point $\left(M_{s}\right)$, input reference values $y_{i j}(i=$ $\left.1,2, \ldots, k ; j=1,2, \ldots, r_{0}\right)$, average values $\left(\bar{y}_{S}\right)$, sensitivity coefficient $(\beta)$, sum of squares difference $(r)$ and ideal proportional function, according to Table 4:

$$
\begin{aligned}
& y_{i j}-y_{s}=\beta\left(M_{i}-M_{S}\right), \\
& \bar{y}_{S}=\frac{y_{s 1}+y_{s 2}+, \ldots,+y_{s y 0}}{r_{0}}, \\
& \beta=\frac{1}{r_{0} r}\left[y_{1}\left(M_{1}-M_{S}\right)+y_{2}\left(M_{2}-M_{S}\right)+\ldots+y_{k}\left(M_{k}-M_{S}\right)\right] \\
& r=\left(M_{1}-M_{S}\right)^{2}+\left(M_{2}-M_{S}\right)^{2}+\ldots+\left(M_{k}-M_{S}\right)^{2} \\
& y-\bar{y}_{S}=\beta\left(M-M_{S}\right) .
\end{aligned}
$$

Table 4: Input values

\begin{tabular}{|l|c|c|c|c|}
\hline Input values & $\boldsymbol{M}_{1}-\boldsymbol{M} \boldsymbol{s}$ & $\boldsymbol{M}_{2}-\boldsymbol{M} \boldsymbol{s}$ & & $\boldsymbol{M}_{\boldsymbol{k}}-\boldsymbol{M} \boldsymbol{S}$ \\
\hline \multirow{5}{*}{ Input sizes } & $y_{11}-\bar{y}_{S}$ & $y_{21}-\bar{y}_{S}$ & $\ldots$ & $y_{k 1}-\bar{y}_{S}$ \\
\cline { 2 - 5 } & $y_{12}-\bar{y}_{S}$ & $y_{21}-\bar{y}_{S}$ & $\ldots$ & $y_{k I}-\bar{y}_{S}$ \\
\cline { 2 - 5 } & $\ldots$ & $\ldots$ & $\ldots$ & $\ldots$ \\
\cline { 2 - 5 } & $y_{1 r 0}-\bar{y}_{S}$ & $y_{2 r 0}-\bar{y}_{S}$ & $\ldots$ & $y_{k r}-\bar{y}_{S}$ \\
\hline Total & $y_{1}$ & $y_{2}$ & & $y_{k}$ \\
\hline
\end{tabular}

The calculation of the $(S / N)$ ratio includes total sum of squares variability $\left(S_{T}\right)$, linear effect of input quantity $\left(S_{\beta}\right)$ and error variability $\left(S_{e}\right)$ :

$$
\begin{aligned}
& S_{\mathrm{T}}=y_{i 1}-\bar{y}_{S}=\sum_{i=1}^{k} \sum_{j=1}^{r_{0}}\left(y_{i j}-\bar{y}_{S}\right)^{2},\left(f=k r_{0}\right), \\
& S_{\beta}=\frac{1}{r_{0} r}\left[y_{1}\left(M_{1}-M_{S}\right)+y_{2}\left(M_{2}-M_{S}\right)+\ldots+y_{k}\left(M_{k}-M_{S}\right)\right]^{2},(f=1) \\
& S_{e}=S_{T}-S_{\beta},\left(f=k r_{0}-1\right) .
\end{aligned}
$$

For example, the quality of the Density Analyzer should be evaluated according to the ideal proportional function with a reference point of $5 \%$ of the standard solution. Solutions of four different densities with four different densities (5 $\%, 10 \%, 15 \%, 10 \%$ ) were observed and the data 
in Table 5. were obtained, after two measurements $\left(R_{l}, R_{2}\right)$.

Table 5: Measured density values

\begin{tabular}{|l|l|l|l|l|}
\hline & \multicolumn{4}{l|}{ Density $\mathbf{M}(\%)$} \\
\hline Measure & 5 & 10 & 15 & 20 \\
\hline $\mathrm{R}_{1}$ & 5.2 & 10.3 & 15.4 & 20.1 \\
\hline $\mathrm{R}_{2}$ & 5.0 & 10.1 & 15.5 & 20.3 \\
\hline
\end{tabular}

With the average $\left(M_{S}=5 \%\right)$, the of the calibration values reference points are obtained according to Table 6:

$$
\bar{y}_{S}=\frac{5.2+5.0}{2 \cdot 5.1} \beta\left(M-M_{S}\right),
$$

Table 6: Measured density values after calibration

\begin{tabular}{|l|l|l|l|l|}
\hline \multirow{2}{*}{} & \multicolumn{4}{l}{ Density $\boldsymbol{M ( \% )}$} \\
\cline { 2 - 5 } & 5 & 10 & 16 & 20 \\
\hline$M-M_{S}$ & 0 & 5 & 10 & 15 \\
\hline \multicolumn{4}{|l}{} \\
\hline $\mathrm{R}_{1}$ & 0.1 & 5.2 & 10.3 & 15.0 \\
\hline $\mathrm{R}_{2}$ & -0.1 & 5.0 & 10.4 & 15.2 \\
\hline Total & 0.0 & 10.2 & 20.7 & 30.2 \\
\hline
\end{tabular}

The obtained results of the analysis of variance are also shown in Table 7:

$$
\begin{aligned}
& S_{T}=0.1^{2}+(-0.1)^{2}+\ldots \\
& \ldots+15,2^{2}=722.35,(f=8), \\
& r_{0} r=2\left(0^{2}+5^{2}+10^{2}+15^{2}\right)=700, \\
& S_{\beta}=\frac{(0 \cdot 0+5 \cdot 10.2+10 \cdot 20.7+15 \cdot 30.2)^{2}}{700}= \\
& =722.1729,(f=1), \\
& S_{e}=S_{T}-S_{\beta}=722.35-722.1729= \\
& =0.1771,(f=7), \\
& V_{e}=\frac{S_{e}}{7}=\frac{0.1771}{7}=0.0253 .
\end{aligned}
$$

Table 7: Summary results of analysis of variance

\begin{tabular}{|l|l|l|l|l|}
\hline Factor & $\boldsymbol{f}$ & $\boldsymbol{S}$ & $\boldsymbol{V}$ & $\boldsymbol{E}[\mathbf{V}]$ \\
\hline$\beta$ & 1 & 722.1729 & 722.1729 & $\sigma^{2}+r_{0} r \beta^{2}$ \\
\hline $\mathrm{e}$ & 7 & 0.1771 & 0.0253 & $\sigma$ \\
\hline Total & 8 & 722.3500 & & \\
\hline
\end{tabular}

$$
y_{i j}=m+\beta\left(M_{i}-\bar{M}\right)+e_{\mathrm{ij}},
$$

How are they calculated: based on ratio $(S / N)$, sensitivity $\left(S_{\beta}\right)$, an average of the linear coefficient $(\beta)$ and linear dependence function it can be concluded that the quality of the Density analyzer is good, due to the positive value of the ratio $S / N=$ $16.10[\mathrm{~dB}]$ :

$$
\begin{aligned}
& S / N=\frac{\frac{1}{700}(722.1729-0.0523)}{0.0253}=40.76, \\
& S / N=10 \log (40.76)=16.10[\mathrm{~dB}], \\
& S_{\beta}=10 \log \frac{722,1729-0,0523}{700}= \\
& =10 \log 1.0316 \\
& \beta=\sqrt{1.0316}=1.015, \\
& y-5.1=1.015(M-5) .
\end{aligned}
$$

The following is obtained: calculated $(S / N=16.10$ $[\mathrm{dB}])$ ratio, estimated regression coefficient $(\beta=$ 1.015) and dependence function $(y-5.1=$ $1.015(M-5))$.

After the calculation, it was found that the quality of the new INSTRUMENT DENSITY ANALYZER with four different densities (5\%, $10 \%, 15 \%, 10 \%)$ can be compared with the correct instrument, due to the positive and higher value of the ratio $(S / N=16.10[\mathrm{~dB}])$

\section{EXAMPLE OF IDEAL LINEAR FUNCTION}

Evaluation of the quality of process results, with an ideal linear function, occurs when there are no special constraints between inputs and outputs, or when the regression line passes through reference data $(M=\bar{M}, y=m)$, usually for completed processes (Selden, 1997). Evaluation of the quality of process results with an ideal linear function, includes input value $M\left(M_{1}, M_{2}, . ., M_{\mathrm{k}}\right)$, input values $y_{i j}\left(\mathrm{i}=1,2, \ldots, k ; j=1,2, \ldots, r_{0}\right)$, number of repetitions of each level of input quantity $\left(r_{o}\right)$, output result $y$ $\left(y_{1}, y_{2}, . ., y_{\mathrm{k}}\right)$, regression coefficient $(\beta)$, mean value $(\bar{M})$ and the sum of squares of difference of input values $(r)$ : 


$$
\begin{aligned}
& m=\bar{y} \\
& \beta=\frac{1}{r_{0} r}\left[y_{1}\left(M_{1}-\bar{M}\right)+y_{2}\left(M_{2}-\bar{M}\right)+\ldots+y_{k}\left(M_{k}-\bar{M}\right)\right] \\
& \bar{M}=\frac{M_{1}+M_{2}+. .+M_{k}}{k}, \\
& r=\left(M_{1}-\bar{M}\right)^{2}+\left(M_{2}-\bar{M}\right)^{2}+. .+\left(M_{k}-\bar{M}\right)^{2}
\end{aligned}
$$

It should be noted that for ideal linear functions, the total variability $\left(S_{T}\right)$ is obtained subtracting the value $\left(S_{m}\right)$ from the total sum of the squares of the individual data, so the variability is the mean:

$$
\begin{aligned}
& S_{T}=y_{11}^{2}+y_{11}^{2}+. .+y_{11}^{2}+S_{m}, \\
& \left(f=k_{r 0}-1\right) . \\
& S_{m}=\frac{\left(\sum y_{i j}\right)^{2}}{k_{r 0}}, \\
& S_{\beta}=\frac{1}{r_{0} r}\left[y_{1}+\left(M_{1}-\bar{M}\right)^{2}+y_{2}\left(M_{2}-\bar{M}\right)^{2}+. .+y_{k}\left(M_{k}-\bar{M}\right)^{2}+. .\right]^{2},(f=1), \\
& S_{e}=S_{T}-S_{\beta},\left(f=k_{r 0}-3\right), \\
& V_{e}=\frac{1}{k_{r 0}-2} S_{e}, \\
& S / \mathrm{N}=10 \log \frac{\frac{1}{r_{0} r}\left(S_{\beta}-V_{e}\right)}{V_{e}} .
\end{aligned}
$$

The calculation of the ratio $(S / N)$ includes the total variability of the average value $\left(S_{m}\right)$, the total linear effect of the input quantity $\left(S_{\beta}\right)$, the error variance $\left(V_{e}\right)$ and the true value of the ratio $(S / N)$ :
For example, the quality of the plastic injection process should be assessed according to a linear function. Two injection processes with four different pressures were observed, with $(\bar{M}=45)$, so the difference between $(M=\bar{M}, y=m)$ in the ANOVA table in Table 8. was analyzed, while the results are shown in Table 9.

$$
\begin{aligned}
& S_{T}=4.608^{2}+4.590^{2}+\ldots+4.702^{2}= \\
& =173.552216,(f=8), \\
& S_{m}=2\left(\frac{9.198+\ldots+9.420}{8}\right)^{2}= \\
& =173.538450,(f=1), \\
& r_{0} r=2\left[(-15)^{2}+(-5)+5^{2}+15^{2}\right]=1,000,
\end{aligned}
$$

$$
\begin{aligned}
& S_{\beta}=\frac{1}{1,000}[(-15) \cdot 9.198+\ldots+15 \cdot 9.420]^{2}= \\
& =0.0132496,(f=1), \\
& S_{e}=S_{T}-S_{\mathrm{m}}-S_{\beta}=173.552216-173.538450- \\
& -0.0132496=0.0005164,(f=6), \\
& V_{e}=\frac{S_{e}}{6}=\frac{0.005164}{6}=0.00008607, \\
& S / N=\frac{\frac{1}{1,000}(0,0132496-0,00008607)}{0,00008607}= \\
& =0.1529, \quad \\
& S / N=10 \log (0.152939)=-8.1547[\mathrm{~dB}] .
\end{aligned}
$$




$$
\begin{aligned}
& m=\frac{37.26}{8}=4.6575, \\
& \beta=\frac{3.64}{1,000}=0.00364, \\
& y=4.6575+0.00364(\mathrm{M}-45) .
\end{aligned}
$$

Table 8: Results of analysis of density variances

\begin{tabular}{|l|l|l|l|l|}
\hline \multirow{2}{*}{} & \multicolumn{4}{|l|}{ Pressure $\left[\mathrm{kg} / \mathrm{cm}^{2}\right]$} \\
\cline { 2 - 5 } & 30 & 40 & 50 & 60 \\
\hline$M=\bar{M}$ & -15 & -5 & 5 & 15 \\
\hline & Measure [mm] & \\
\hline $\mathrm{R}_{1}$ & 4.608 & 4.640 & 4.682 & 4.718 \\
\hline $\mathrm{R}_{2}$ & 4.590 & 4.650 & 4.670 & 4.702 \\
\hline Total & 9.198 & 9.290 & 9.352 & 9.420 \\
\hline
\end{tabular}

Table 9: Summary results of variance analysis

\begin{tabular}{|l|l|l|l|l|}
\hline Factor & $\boldsymbol{f}$ & $\boldsymbol{S}$ & $\boldsymbol{V}$ & $\boldsymbol{E}[\mathbf{V}]$ \\
\hline$m$ & 1 & 173538450 & 173538450 & $\sigma^{2}+4\left(2 \sigma_{m}^{2}\right)$ \\
\hline$\beta$ & 1 & 0.013496 & 0.013496 & $\sigma^{2}+r_{0} r \beta^{2}$ \\
\hline$e$ & 6 & 0.0005164 & 0.0000861 & $\sigma^{2}$ \\
\hline Total & 8 & 173552216 & & \\
\hline
\end{tabular}

Estimation of the average $(m=4.6575)$ and the sensitivity coefficient $(\beta=0.00364)$ gave a linear function $y$.

After the calculation, it was found that the quality of the PLASTIC INJECTION PROCESS was not be good, due to the negative and small value of the ratio $(S / N=-8.1547[\mathrm{~dB}])$.

\section{RESULTS AND CONCLUSIONS}

In traditional engineering, only the quality of measuring instruments and the quality of completed processes ( $P C I$ precision or accuracy indices, $P P I)$ can be successfully defined, while the quality of process results (semi-finished product, product, software, service) can only be described (has or does not have the required quality), good or bad quality, better or worse quality). In modern quality consideration, the quality of process results is now defined by the number of decibels [dB], according to the discovery of the Japanese scientist Genichi Taguchi, with the methods of Robust Technology Development and Standard Ratio $(S / N)$. The standard $(S / N)$ ratio (signal/noise ratio, $S / N$ ) establishes the appropriate ratio of input quantity $(S)$ and variability $(N)$, which Taguchi used for application in the communications industry, to check the quality of results. starting from the fact that the radio receives a signal or a wave of voice that is broadcast from broadcasting stations and converts it into sound, the voice is the input quantity (signal), the received voice is the output signal (response), where the input is mixed in space with the output signal variability (noise), so the sound quality is expressed by the ratio of the input signal and the variability in decibels [dB]. In this paper, the definition of the quality of process results with one input quantity and continuous characteristics with three illustrative examples is considered.

After the performed calculations, the following results were achieved:

- now the qualities of the process results (semifinished product, product, software, service) can be defined, which previously could only be described (there is or is not the required quality, good or bad quality, better or worse quality),

- it was determined that the quality of the new DENSITY ANALYZER INSTRUMENT with three different densities $(30[\mu \mathrm{m}], 80[\mu \mathrm{m}], 90$ $[\mu \mathrm{m}])$ cannot be compared with the correct instrument, due to the negative and small value of the ratio $(S / N)=-9.29[\mathrm{~dB}])$.

- it was found that the quality of the new INSTRUMENT DENSITY ANALYZER with four different densities $(5 \%, 10 \%, 15 \%, 10 \%)$ can be compared with the correct instrument, due to the positive and higher value of the ratio $(S / N)=16.10[\mathrm{~dB}])$.

- It was found that the quality of the PLASTIC INJECTION PROCESS is not good, due to the negative and small value of the ratio $(S / N)=$ $-8.1547[\mathrm{~dB}])$.

\section{REFERENCES}

Atkinson, A. C., Donev, A. N., \& Tobias, R. D. (2007). Optimum Experimental Designs with SAS. Oxford University Press. pp.511+xvi.ISBN978-0-19929660-6.

Box, G. E. P., \& Draper, N. (2007). Response Surfaces, Mixtures, and Ridge Analyses. Second Edition of Empirical Model-Building and Response Surfaces, 1987, Wiley.

Ewing, B., Hillier, L., Wendl, M.C., \& Green, P. (1998). Base-calling of automated sequencer traces using phred. I. Accuracy assessment.Genome Research.8(3): 175-185. https://doi.org/10.1101/gr.8.3.175.PMID9521921. 
Goos, P. (2002).The Optimal Design of Blocked and Split-plot Experiments. Lecture Notes in Statistics. 164. Springer. ISBN 978-0-387-95515-5

Logothetis, N., \& Wynn, H.P. (1989). Quality Through Design: Experimental Design, Off-line Quality Control, and Taguchi's Contributions. Oxford University Press, Oxford Science Publications. ISBN 0-19-851993-1

Moen, R. D., Nolan, T. W., \& Provost, L. P. (1991). Improving Quality Through Planned Experimentation. McGraw-Hill Science, Engineering \& Mathematics. ISBN 0-07-042673-2

Montgomery, D. C. (2005). Design and Analysis of Experiments, Ch. 9. 6th Edition. Wiley.

Nair, V. N. (1992). Taguchi's parameter design: a panel discussion. Technometrics, 34(2), 127-161. https://doi.org/10.1080/00401706. 1992. 10484904.

Pukelsheim, F. (2006). Optimal Design of Experiments. SIAM. ISBN 978-0-89871-604-7. https://epubs.siam.org/doi/pdf/10.1137/1.978089871 9109.bm

Hardin, R. H, \& Sloane, N. J. A. (1993). A New Approach to the Construction of Optimal Designs. Journal of Statistical Planning and Inference, 37, 339-369. https://doi.org/10.1016/03783758(93)90112-J

Rosa, J. L., Robin, A. S., Baldan, M. B., Carlos, A., \& Peres, M. P. (2009). Electrodeposition of copper on titanium wires: Taguchi experimental design approach. Journal of Materials Processing Technology, 2009(3), 1181-1188. https://doi.org/10.1016 j.jmatprotec.2008.03.021

Selden, P. H. (1997). Sales process engineering: A Personal Workshop. Milwaukee, Wisconsin: ASQ Quality Press. ISBN 0-87389-418-9.
Sreenivas, R. R., Ganesh, K. C., Prakasham, R. S., \& Hobbs, P. J. (2008). The Taguchi methodology as a statistical tool for biotechnological applications: A critical appraisal. Biotechnology Journal, 3(4): 510523. https://doi.org/10.1002biot.200700201.PMID183205 63.S2CID26543702.

Taguchi, G. (1986). Introduction to Quality Engineering: Designing Quality into Products and Processes. Tokyo, Japan: Asian Productivity Organization. ISBN 978-928-3310846.

Taguchi, G. (1995). Quality engineering (Taguchi methods) for the development of electronic circuit technology. IEEE Transactions on Reliability. IEEE Reliability Society, 44(2), 225-229. https://doi.org/10.1109/24. 387375.

Taguchi, G. (1992). Taguchi on Robust Technology Development: Bringing Quality Engineering Upstream. ASME Press. ISBN 978-0791800287.

Taguchi, G., Chowdhury, S., \& Wu, Y. (2005). Taguchi's Quality Engineering Handbook. John Wiley. ISBN 978-0471413349.

Taguchi, G., Chowdhury, S. \& Wu, Y. (2000). The Mahalanobis-Taguchi System. McGraw Hill Professional. ISBN 978-0071362634.

Taguchi, G., \& Rajesh J. (2002). The MahalanobisTaguchi Strategy: A Pattern Technology System. John Wiley \& Sons. ISBN 978-0471023333.

Taguchi, G., Rajesh J., \& Taguchi S. (2004). ComputerBased Robust Engineering: Essential For DFSS. American Society for Quality. ISBN 9780873896221.

Wu, C. F. J. \& Hamada, M. (2002). Experiments: Planning, Analysis, and Parameter Design Optimization. Wiley. ISBN 978-0471255116.

\section{VREDNOVANJE KVALITETA PROIZVODA SA DECIBELIMA}

U savremenom inženjerstvu kvaliteta, kvalitet rezultata procesa, kvalitet mernih instrumenata $\mathbf{i}$ kvalitet završenih procesa razmatraju se prema njihovim karakteristikama kvaliteta. Međutim, u okvirima tradicionalnog inženjeringa samo kvalitet mernih instrumenata i kvalitet završenih procesa (indeksi preciznosti ili tačnosti $P C I, P P I)$ može se uspešno definisati), dok se kvalitet rezultata procesa (poluproizvod, proizvod, softver, usluga) može opisati samo ,ima ili nema traženi kvalitet"“, dobar ili loš kvalitet, bolji ili lošiji kvalitet. U savremenom razmatranju kvaliteta, kvalitet rezultata procesa sada se definiše brojem decibela (dB), prema otkriću genijalnog japanskog naučnika Geničija Tagučija (1924-2012), metodama robusnog razvoja tehnologije i standardnog odnosa $(\mathrm{S} / \mathrm{N})$. U ovom radu razmatra se definisanje kvaliteta rezultata procesa sa jednom ulaznom varijablom i kontinuiranim karakteristikama sa tri ilustrativna primera.

Ključne reči: Inženjering kvaliteta; Kvalitet rezultata procesa; Kontinualne karakteristike. 